\title{
THE GENTLE ART OF MENTORING IN HIGHER EDUCATION
}

FACILITATING SUCCESS IN THE ACADEMIC WORLD

\author{
Nancy H. Barry \\ Auburn University
}

Senior faculty working together to support the professional development of new faculty colleagues is a much more efficiont use of time and effort in comparison to dealing with a new faculty member who flounders because be or she has not been prepared to function effectively within the culture of the department. Increased professional expectations brought about through digital technology, budget issues, and other factors are contributing to a stressful and complex working environment for all faculty, and new faculty are particularly vulnerable. Investing time and effort in a formal, structured mentoring program can ultimately increase productivity for all.

o

College programs across the United States produce graduates who are generally well trained in the techniques of their content disciplines, scholarship, and research. However, most of these students complete their degree programs and embark on academic careers with no formal training in how to be a productive and successful faculty member. Although there is no sure way to guarantee a successful academic career, mentoring programs can provide needed support in negotiating the challenges of 
successfully balancing the responsibilities of teaching, research, creative work, outreach, service, and collegiality, not to mention the daunting realities of navigating the pitfalls of university politics and protocol (Mullen \& Forbes, 2000; Mullen \& Hutinger, 2008). This chapter provides a brief review of the literature and a review of selected successful mentoring programs as frameworks for discussing practical implications of mentoring as professional practice in college teaching.

In a formal academic mentoring relationship, the novice faculty member receives support and guidance from a more experienced colleague (Luna \& Cullen, 1995; Mullen \& Hutinger, 2008). The term mentor is generally attributed to the story of Odysseus (Harnish \& Wild, 1994). According to Greek mythology, when Odysseus departed for the Trojan War, he charged his old friend Mentor with looking after his son, Telemachus, as well as watching over his wife, household, and possessions. Mentor's influence over Odysseus's son was so profound that when the goddess Athena visited Telemachus, she disguised herself as Mentor to gain the young man's trust. In this guise, she advised Telemachus to stand against his mother's suitors and go abroad to discover his father's fate ("Mentor," 2010). Roberts (2000), however, disputes the popular notion that the modern use of mentor originated with The Odyssey, citing Fénélon's Les aventures de Télémaque, written in 1699, as the more contemporary origin of the term.

\section{Review of the Literature}

Savage, Karp, and Logue (2004) define mentoring as "a process in which one person, usually of superior rank and outstanding achievement, guides the development of an entry-level individual" (p. 21). The ways in which mentoring occurs in higher education vary, ranging from natural and spontaneous professional relationships that develop between individuals, to very formal and systematic programs with clearly defined roles, expectations, and evaluation processes (Leslie, Lingard, \& Whyte, 2005; Mullen \& Hutinger, 2008). These different types of mentoring are not mutually exclusive. It is not unusual to see situations in which the same individual participates in a formal university mentoring program while also seeking counsel from an informal mentor, either on- or off-campus (Leslie et al., 2005; Mullen \& Hutinger, 2008; Savage et al., 2004).

Opportunities for developing mentoring relationships with on-campus colleagues may be becoming more limited. The decline of the tradition of faculty clubs and faculty common rooms, coupled with increasing dependence on electronic communication and the Internet, have contributed to 
a culture in which "professors often feel greater allegiance to fellow specialists across the country than to their colleagues down the hall" (Schneider, 1997, p. A12). The literature depicts situations in which junior faculty frequently report feelings of isolation and disenfranchisement at their own institutions (Driscoll, Parkes, Tilley-Lubbs, Brill, \& Bannister, 2009; Mandernach, 2006; Trower \& Gallagher, 2008; Tysome, 2007), forcing them to look elsewhere for "support from a community of scholars that they have not found" on their own campuses (Savage et al., 2004, p. 22).

While opportunities for on-campus interaction with colleagues may be declining, those for virtual interaction are expanding. Innovations in digital technology, coupled with economic concerns for both students and degree-granting institutions, are triggering changes in the way that a college campus and the academic culture within a college, department, or program are being defined (Finkelstein, Frances, Jewett, \& Scholz, 2000). These changes may have a profound impact on faculty role development and socialization. As a result of the virtual classroom, new understandings of collegiality and what it means to be a faculty member are emerging and expanding beyond the brick-and-mortar classroom. Just a few years ago, many academic professionals viewed virtual degrees from online institutions with skepticism and concern that academic rigor may have been compromised. In contrast, today we see the top academic institutions in the United States offering (and expanding) their distance programs. Distance education provides both advantages and challenges for students and faculty (Conciecao-Runlee, 2001). However, on many campuses, the reward structure for faculty has not yet caught up with the increasing demands on faculty to develop and maintain distance programs (Orr, Williams, \& Pennington, 2009; Simpson, 2010). New faculty may need mentoring to help them balance the contemporary challenges of the virtual classroom with traditional expectations within their unit.

This trend toward distance instruction represents a significant paradigm shift in terms of the traditional on-campus faculty academic culture and the ways in which teaching, collegiality, and service have been defined. This situation is compounded by the fact that these changes have happened relatively quickly. It is likely that the field of college teaching will eventually reconcile new faculty expectations regarding technology and distance instruction within the traditional on-campus culture of the institution and the tenure and promotion process. However, it appears that at present, the opportunity, or expectation, to teach courses using distance technology may be contributing to social isolation and a level of remoteness from colleagues and may compromise a faculty member's 
ability to participate fully in the on-campus culture and traditional expectations of the department and institution (Conciecao-Runlee, 2001; Mandernach, 2006).

Despite some of these challenges, successful mentoring in higher education is possible. Certainly many individuals seek out informal mentoring relationships, which may be quite beneficial. An important advantage of informal mentoring is that usually both the mentor and mentee selfselected to engage in the process and therefore are less likely to experience interpersonal conflict or communication problems (Leslie et al., 2005; Mullen \& Forbes, 2000).

Leslie et al. (2005) identified several advantages associated with informal peer-based mentoring within the medical profession. Mentoring among peers provides professional guidance and support within the relative safety of nonhierarchical relationships, as opposed to a situation in which the mentor may hold political power over the mentee. Informal mentoring among peers may also promote a supportive environment within the workplace and contribute to a generalized attitude among physicians that help is available from colleagues when needed.

However, while research acknowledges that informal mentoring relationships can be highly beneficial and productive, the consensus among most scholars is that a more formalized mentoring process is necessary to ensure that all junior faculty have equitable access to mentoring (Harnish \& Wild, 1994; Leslie et al., 2005; Mullen \& Hutinger, 2008; Savage et al., 2004). Formal mentoring has been identified as an important tool for achieving professional socialization for new academic colleagues (Mullen \& Forbes, 2000) and has been encouraged by leading professional associations. The American Association for Higher Education, for example, had endorsed mentoring by senior faculty as good practice at colleges and universities (Sorcinelli, 2000).

Numerous studies have addressed the importance of providing formal mentoring processes for entry-level college faculty, but the research also points out that the mentoring of our new faculty colleagues should begin before they take that first college-level position (Gibson, 2006; Mullen \& Hutinger, 2008; Savage et al., 2004). The process of mentoring colleagues should begin with doctoral students: "Professional socialization (including ethical issues) needs to be built into the academic mentoring of doctoral students who typically do not realize what is required of faculty in order to be successful in the academy" (Mullen \& Forbes, 2000, p. 45). However, not all scholars support the notion that formal mentoring should be provided for university faculty. In their essay in Teaching of Psychology, Selby and Calhoun (1998) express an alternative view, 
stating that formal mentoring programs drain time and resources that should be invested in other professional endeavors and arguing that this type of professional preparation should be the responsibility of the graduate program: "If colleges and universities are now systematically producing psychologists who are not ready to take their places as fully functioning colleagues, then perhaps what is needed is not the formalized paternalism of mentoring programs, but an improvement in the quality of doctoral training in psychology" (p. 211).

Despite possible pitfalls (such as Selby and Calhoun's concern about mentoring as a type of "formalized paternalism"), the research literature strongly supports the need for providing structured mentoring for our future colleagues while they are still graduate students as well as a formalized mentoring process for new faculty. But what is the best way to achieve this?

In their article describing a successful mentoring program at Clarion University of Pennsylvania, Savage et al. (2004) provide a useful summary of the literature. According to this literature review, a mentoring program should:

o Empower new and continuing faculty by supporting their professional growth and renewal.

o Promote faculty satisfaction through what has been described in recent literature as a dialectical relationship with peers and senior faculty that can foster a sense of community.

- Attract, retrain, and facilitate promotion of new faculty by thoroughly explaining the university's tenure and promotion systems and by introducing new faculty to unique organizational cultures and definitions of work responsibilities.

- Provide opportunities for interactions between junior and senior faculty to facilitate mutual respect and avoid counterproductive divisions between old and young professors.

o Meet "entry level survival needs" of new faculty by providing information about departmental and university sociopolitical culture.

- Assist new faculty members in developing and balancing their professional commitments to research, creative activity, teaching, outreach, and service.

This list provides useful guidelines for developing successful mentoring programs, but formal pairings between mentees and mentors do not 
always work out well. Differences in goals, experience, dispositions, and perceived power relationships (Donnelly \& McSweeney, 2011; Hansman, 2009) raise ethical dilemmas and may contribute to conflict between the mentee and the mentor. Certainly most experienced university faculty and administrators are aware of dismal stories in which a mismatch between mentor and mentee yielded unproductive or even tragic results. However, despite some possible pitfalls, as the roles and expectations of college faculty become increasingly complex in a world where new communications technologies may be contributing to physical isolation in the workplace, it is clear that a structured approach to mentoring is necessary to ensure the professional socialization and ultimate academic success of our graduate students and our colleagues.

\section{Examples of Successful Mentoring Programs}

In preparing this chapter, I searched both the Internet and academic databases to identify models of mentoring programs in colleges and universities across the United States. This search revealed that mentoring programs currently in place at higher learning institutions around the country vary widely. Some are very informal and unofficial, such as the program at the University of Iowa's College of Engineering, which explicitly states, "The main purpose of the mentor program is to provide unofficial, informal, and confidential assistance and suggestions to tenure-track faculty members... . Suggestions made by a mentor are informal and unofficial. All participants are free to terminate their participation in the program at any time" (University of lowa College of Engineering, n.d.).

Other programs are much more formal and structured, with regularly scheduled events and ongoing evaluation, such as the faculty mentoring program in the College of Education at Kansas State University, which includes "formal mentor-mentee matches, monthly lunches, and other activities" (Kansas State University College of Education, n.d.). After being interviewed and participating in a discussion with the director and the mentoring committee, new tenure-track faculty are matched with one or two mentors. This program includes scheduled events and formal evaluation, but the exact nature of the mentoring relationship is determined by each mentor and mentee team.

The College of Education New Faculty Mentoring Program at the University of South Florida is another example of a "formalized, systematic approach to mentoring" (Mullen, 2006, p. 3). Each new faculty member is assigned two mentors, one from her or his own department (assigned by the department chair) and one from outside the department (assigned 
by the college's faculty mentoring coordinator). The faculty mentoring coordinator organizes collegewide events such as a meet-and-greet luncheon each fall, faculty research panels, grant-writing workshops, and other specialized activities. Faculty mentors are responsible for maintaining regular contact with their mentee. Program evaluation includes surveys completed by both mentors at the beginning and end of each year. Written feedback is also solicited from the mentees.

I found the Northern Illinois University New Faculty Mentoring Program Web site to be particularly thorough and informative (Northern Illinois University, n.d.), with detailed lists of goals for both mentors and mentees, suggested mentoring activities, descriptions of the process, "The 10 Commandments of Mentoring," and a list of useful links. The Web site describes this program as "voluntary" and "not meant to be a substiture for existing mentoring programs at the department or college levels but can be a supplement to those programs" (Northern Illinois University, n.d.).

A number of higher education institutions offer mentoring programs specifically for women and minorities (Gibson, 2006; Thomas, 2005; Wasburn, 2007). As Luna and Cullen (1995) have documented, effective mentoring emphasizes the importance of people within the educational environment by acknowledging and helping to reconcile individual perspectives and situations. Mentoring programs can serve to empower women and minorities to become leaders, ultimately benefiting both individual faculty members and the institution as a whole.

Exemplary Junior Faculty Mentoring Programs (Thomas, 2005) for the Yale University Women Faculty Forum presents the results of a review of junior faculty mentoring programs at seventeen of Yale's peer institutions. Ultimately, five programs were identified as being exemplary: Emory University, Passages Program; University of California San Diego, Faculty Mentoring Program; Stanford Medical School, Faculty Mentoring; University of Wisconsin, Women Faculty Mentoring Program; and University of Oregon, Women Faculty Resource Network.

Among these five programs, two were designed particularly for women, one was particularly for medical faculty, and one was originally designed for women but was eventually expanded to include all junior faculty. Although each of these programs was unique and tailored to the needs of a particular population and academic setting, they had many commonalities:

- Structured process and procedures

o A formal process for matching mentors with mentees 
- Regular meetings between mentor and mentee

- Formal goal setting

- Formal group meetings for specific training

o Informal group meetings for socialization and information exchange

- Detailed guidelines defining the roles of mentor and mentee

o A comprehensive Web site providing easy access to information

o Provision for changing mentors if the relationship does not work

\section{Putting Research into Practice: Reflections on a Pilot Program}

At my university, our department has had a long-standing tradition of mentoring, with the department head assisting in pairing each new faculty member with a more experienced faculty member to assist with professional development and help the new faculty member become a productive departmental citizen. When I joined our faculty as a new department head in 2007 , with several new faculty nearing the time for their tenure or promotion vote, as well as several faculty searches in progress, I quickly became aware of our acute need for a more formalized mentoring process. We looked to the literature and models of successful practice and were also fortunate to be able to build on some excellent recommendations from a faculty committee. Opportunities for faculty input were an important part of this process as our mentoring policy was developed over several months.

Our departmental mentoring program begins with the new faculty member and the department head working together to select three tenured faculty members for nomination to serve on a mentoring committee (based on research interests, as well as balancing faculty workloads and teaching responsibilities). The final mentoring committee is based on mutual agreement by the department head, the faculty member, and the committee members, with the understanding that a "no-fault" policy remains in place in which the mentoring committee members may choose to step down or may be replaced if that is deemed in the best interest of the candidate or the committee member as the process moves forward. The mentoring committee works directly with the new faculty member in important professional development activities such as preparing for annual job performance reviews and developing the promotion and tenure dossier. 
In practice, making changes to the mentoring committee has presented some serious challenges that we have not yet resolved. Although the option to request a change in mentoring committee members is clearly available as a matter of policy, this may be difficult to achieve in reality because a candidate may not wish to acknowledge formally (and perhaps exacerbate) any disagreements that may have emerged with a member of the mentoring committee. A change in mentoring committee membership is rather straightforward and nonconfrontational when it is necessitated by differences in research interests or other mutually acknowledged professional or practical reasons, such as scheduling conflicts or a mentoring committee member being off campus for sabbatical. However, when some perceived political or personal conflict between the candidate and an assigned mentor may be at play, the candidate may be placed in a no-win situation in which the option of keeping the disagreeable faculty member on the mentoring committee may seem to hold no worse consequences than exacerbating already strained professional relations by formally requesting a change of committee. Thankfully, these situations have been rare, but we have not yet succeeded in developing a policy that genuinely functions as "no fault" when serious conflicts arise between the candidate and an assigned mentor.

This pilot mentoring program is not presented as a model, but rather as an example of a practical application of the literature; only time will tell if our mentoring program has been effective (as gauged by the success of our new faculty). Certainly it is likely that as we learn through experience, our faculty will revisit our policies and consider making some adjustments. Although we have not yet conducted a formal evaluation of our program, preliminary observations seem consistent with the literature. Our new faculty report that the mentoring program is generally beneficial and that they feel well informed about protocol and policies within our department and college. These observations are similar to Mullen and Hutinger's (2008) findings that most participants (both mentors and mentees) believed that they had benefited from a formal mentoring program.

We are also observing considerable variation among mentee-mentor teams in the level of both perceived and observed success. One important factor appears to be the mentee's role in the process. The most successful mentoring teams seem to be those in which the mentee assumes a very active role (for example, frequently contacting mentors, initiating meetings, submitting unsolicited materials to the mentors for review), while teams in which the mentee assumes a more passive role (for example, waiting for the mentor to take the initiative to schedule all meetings, 
request copies of articles or the $\mathrm{CV}$ ) do not appear to be as successful. As observed in the literature, the most effective mentoring relationships appear to be those in which participants actively engage in a two-way process with clearly defined expectations for both mentor and mentee (Mullen \& Hutinger, 2008; Thorndyke, Gusic, \& Milner, 2008).

\section{Conclusion}

Engaging in formal mentoring can be time-consuming, but the potential benefits far outweigh the costs. The prospect of senior faculty working together to support the professional development of our new faculty colleagues represents a proactive approach-a much more efficient use of time and effort in comparison to the grueling and emotionally draining prospect of dealing with a new faculty member who flounders because he or she has not been prepared to function as an effective citizen within the culture of the department and the campus. Increased professional expectations brought about through digital technology (distance courses, e-mail), budget issues (limited funding, increased pressure on faculty to generate external funding), and other factors are contributing to an increasingly complex working environment for all faculty, but new faculty are particularly vulnerable (Mullen \& Hutinger, 2008). Investing time and effort in a formal, structured mentoring program can ultimately increase productivity for all and may contribute to a more collegial and pleasant departmental culture.

\section{REFERENCES}

Conciecao-Runlee, S. (2001). A phenomenological study of college faculty experiences derived from teaching in a computer-mediated environment when there is an absence of physical presence. Paper presented at the Annual Meeting of the Adult Education Research Conference, Lansing, MI. (ED481589)

Donnelly, R., \& McSweeney, F. (2011). From humble beginnings: Evolving mentoring within professional development for academic staff. Professional Development in Education, 37(2), 259-274.

Driscoll, L. G., Parkes, L. A., Tilley-Lubbs, G. A., Brill, J. M., \& Bannister, V.R.P. (2009, February). Navigating the lonely sea: Peer mentoring and collaboration among aspiring women scholars. Mentoring and Tutoring: Partnership in Learning, 17(1), 5-21.

Finkelstein, M. J., Frances, C., Jewett, F. I., \& Scholz, B. W. (2000). Dollars, distance, and online education: The new economics of college teaching and learning. Washington, DC: American Council on Education, Oryx Press. 
Gibson, S. K. (2006). Mentoring of women faculty: The role of organizational politics and culture. Innovative Higher Education, 31(1), 63-79. doi:10.1007/s10755-006-9007-7.

Hansman, C. A. (2009). Ethical issues in mentoring adults in higher education. In E. J. Burge (Ed.), New directions for adult and continuing education: No. 12.3. Negotiating ethical practice in adult education (pp. 53-63). San Francisco, CA: Jossey-Bass.

Harnish, D., \& Wild, L. A. (1994). Mentoring strategies for faculty development. Studies in Higher Education, 19(2), 191-202.

Kansas State University College of Education. (n.d.) Faculty mentoring program. Retrieved from http:/coe.ksu.edu/about/govern/mentoring.htm

Leslie, K., Lingard, L., \& Whyte, S. (2005). Junior faculty experiences with informal mentoring. Medical Teacher, 27(8), 693-698.

Luna, G., \& Cullen, D. L. (1995). Empowering the faculty: Mentoring redirected and renewed. ASHE-ERIC Higher Education Report series 95-3 (Volume 24-3).

Mandernach, B. J. (2006, August). Confessions of a faculty telecommuter: The freedom paradox. Online Classroom, 3-8.

Mentor. (2010). Wikipedia. Retrieved from http://en.wikipedia.org/wiki/ Mentor

Mullen, C. A. (2006). Mentoring guide for new and experienced faculty in education. Retrieved from http://www.coedu.usf.edu/main/faculty/ documents/MentoringBooklet07_08.pdf

Mullen, C. A., \& Forbes, S. A. (2000). Untenured faculty: Issues of transition, adjustment and mentorship. Mentoring and Tutoring, 8(1), 31-46.

Mullen, C. A., \& Hutinger, J. L. (2008). At the tipping point? Role of formal faculty mentoring in changing university research cultures. Journal of In-Service Education, 34(2), 181-204.

Northern Illinois University. (N.d.). New faculty mentoring program. Retrieved from http:/www.niu.edu/facdev/services/newfacmentoring.shtml

Orr, R., Williams, M. R., \& Pennington, K. (2009). Institutional efforts to support faculty in online teaching. Innovative Higher Education, 34, 257-268.

Roberts, A. (2000). Mentoring revisited: A phenomenological reading of the literature. Mentoring and Tutoring, 8(2), 145-166.

Savage, H. E., Karp, R. S., \& Logue, R. (2004, Winter). Faculty mentorship at colleges and universities. College Teaching, 52(1), 21-24.

Schneider, A. (1997, June 13). Empty tables at faculty club worry some academics. Chronicle of Higher Education, A12.

Selby, J. W., \& Calhoun, L. G. (1998). Mentoring programs for new faculty: Unintended consequences? Teaching of Psychology, 2.5(3), 210-211. 
Simpson, C. M. (2010). Examining the relationship between institutional mission and faculty reward for teaching via distance. Online Journal of Distance Learning Administration, 1.3(1), 1-13.

Sorcinelli, M. D. (2000). Principles of good practice: Supporting early-career faculty: Guidance for deans, department chairs, and other academic leaders. Washington, DC: American Association for Higher Education. Thomas, R. (2005). Exemplary junior faculty mentoring programs. Retrieved from http://www.yale.edu/wff/pdf/ExemplaryJuniory\%20Faculty $\% 20$ MentoringPrograms.pdf

Thorndyke, L. E., Gusic, M. E., \& Milner, R. J. (2008). Functional mentoring: A practical approach with multilevel outcomes. Journal of Continuing Education in the Health Professions, 28(3), 157-164.

Trower, C. A., \& Gallagher, A. (2008, November 4). Why collegiality matters. Chronicle of Higher Education, A50-A51.

Tysome, T. (2007, January 26). The common room shapes ideas. Times Higher Education Supplement, p. 9.

University of Iowa College of Engineering. (N.d.). Faculty mentor program. Retrieved from http://www.engineering.uiowa.edu/faculty-staff/ mentor-program.php

Wasburn, M. H. (2007). Mentoring women faculty: An instrumental case study of strategic collaboration. Mentoring and Tutoring, 1.5(1), 57-72. 